attention to this point. The cold spring no doubt reduced bird song considerably in some localities. Several of the best-filled forms came in from clergymen, but fortunately a greater list of observers has been obtained for the repeat of the survey now under progress, especially from Ireland. Most parts of England are fairly well represented. A good many observations, however, have been kept by people whose weekday hours of observation are very limited, especially during the short winter days.

\section{Agricultural Meteorology in India}

IN the report of the Agricultural Meteorology Section, India Meteorological Department, for the period August 22, 1935-March 31, 1937, it is stated that after reviewing the work done during the first three years of the scheme, the Imperial Council of Agricultural Research communicated to the Government of India a resolution to the effect that the Agricultural Meteorology Section should now become one of the permanent activities of Government, and that proposals for giving effect to this resolution are now under consideration by the Government of India. Work on the experimental or biological aspects of agricultural meteorology, and the maintenance of co-operation with agricultural institutions and workers in India, have been the principal concerns of the section during the period under review, the biological work being carried on mainly at the Central Agricultural Meteorological Observatory at Poona. Among subjects of research were the invisible condensation of water vapour on the soil at Poona, made evident by the decrease during the night in clear weather of water vapour in the layers of air just above the bare ground and by the increase of surface soil moisture to a maximum just before sunrise without visible deposition of dew. It was found that of all samples of soil tested, the black cotton soil of India was, when desiccated, the most efficient absorber of moisture. Researches carried out into the cooling of the earth's surface and of the lower layers of the atmosphere at night in clear weather led to the discovery that at Poona in winter the air temperature has a minimum some distance above the ground. The radiation received from the sun and sky on unit area of a horizontal surface near the ground was measured by means of a Moll solarigraph, and from the records obtained a diagram was constructed showing the intensity of the radiation at different hours of the day in different months.

\section{Uni-directional Lighting on Roads}

THE increasing use of double carriage-way arterial roads has given new problems to the street lighting engineer. Some of these are discussed in a paper on the revealing power of street lighting installations read by J. M. Waldram to the Illuminating Engineering Society on November 8 . On a double carriage-way road where each carriage-way carries traffic proceeding in one direction only, an ordinary street lantern throws much of its light in the direction where it may be doing no good, that is, in the same direction as the traffic flow. This light is not only wasted, but sometimes also does harm by lighting up vertical surfaces and reducing their contrast against the bright background of the road surface. Elimination of light sources not actively producing road brightness, should result in a great increase of comfort to the drivers. The G.E.C. Research Laboratories have evolved a system of uni-directional lighting which they have tested on the carriage-way of the Great Chertsey Road in the Twickenham area. On this road the standards exist on a double staggered formation; the beight of the lantern is $25 \mathrm{ft}$. and the average spacing of the standards about $189 \mathrm{ft}$. Each lantern was equipped with a 250 -watt horizontal burning lamp and was uni-directional. Both visibility and revealing power were found to be very good. Driving in the opposite direction on the other carriage-way, the road lighted with back cut-off lanterns disappeared completely. Traffic moving on it could be distinguished quite easily by the vehicle lights, but apart from this the impression produced was that of driving down a single carriage-way road with no traffic in the oncoming direction. The back cut-off lanterns on the other carriage-way were completely invisible. The conclusions drawn are that it is practicable to light a 'one-way' road with lanterns giving light only in the direction opposed to the traffic. An installation of this nature saves 50 per cent of lamp wattage.

\section{Loud-speaker Systems on Railways}

LOUD-SPEAKER systems are being installed on an ever-increasing scale on railway platforms. A critical discussion of them by $O$. Vogel and $K$. Rothe is given in the second number for 1938 of the quarterly Review published by Siemens and Halske. Until quite recently, orders were shouted to the shunters by the shunting foreman or optical signals were employed. But these methods had certain drawbacks. Shouting was the most satisfactory, partly because it is independent of weather or illumination but mainly because it is heard by the shunters in any position. The transmission of orders by means of loud-speakers is an improvement as it ensures a uniform distribution of ample acoustical energy over the entire shunting yard, and all the requirements of safety and speed are satisfied. The old but satisfactory method of calling out times of departure in railway station waiting-rooms could never be entirely replaced by means of optical devices. The introduction of loud-speaker systems has now supplemented optical train indicators very helpfully and these devices are at the same time available for many other kinds of announcements. The authors also discuss portable loud-speaker systems suitable for race-courses, etc., where the normal traffic is small. To ensure the complete success of a stationary system, it is necessary to study the local conditions in every case. In halls, waiting-rooms and corridors, difficulties are often encountered owing to echoes.

\section{Thickness of Metal Walls}

A Paper by B. M. Thornton and Prof. W. M. Thornton, upon which written discussions are to be sent to the secretary of the Institution of Mechanical Engineers before January 31, 1939, gives a method 